\title{
A EXPERIÊNCIA DE UMA RONDONISTA SOBRE A LUZ DOS SABERES DE PAULO FREIRE
}

\author{
Scheila Mai \\ Universidade do Estado de Santa Catarina (UDESC) \\ Campus Chapecó \\ scheilamai@hotmail.com
}

\begin{abstract}
RESUMO
Introdução: o Núcleo Extensionista Rondon - NER/UDESC, como uma das principais ações de Extensão da Universidade do Estado de Santa Catarina (UDESC), vem possibilitando o intercâmbio dos acadêmicos em diferentes áreas de conhecimento e a inserção da universidade em diversos cenários do estado de Santa Catarina e de outros estados da federação. Objetivo: relatar a contribuição do Rondon no processo formativo, de forma leve e baseada em um diálogo de descobertas dos referenciais teórico de Paulo Freire. Resultados: foram quatro Operações vivenciadas pelo Núcleo Extensionista Rondon UDESC, três delas como acadêmica do curso de enfermagem do Centro Oeste Catarinense e uma dela compondo junto com um colega na coordenação da Operação. Na diversidade dos extensionistas dos diferentes núcleos do saber, desenvolvemos inúmeras atividades com diferentes indivíduos desde bebês, crianças, adolescentes, jovens, adultos até idosos. Na diversidade da comunidade, foi necessário adaptar as diferentes abordagens como para escolares, profissionais de saúde, profissionais da educação, servidores públicos, lideranças comunitárias, pessoas com necessidades especiais, pessoas em ambientes institucionalizados outras hospitalizadas, pessoas vivendo em locais de difícil acesso, entre outras. Foi necessário integrar os diferentes setores da sociedade como a educação, cultura, saúde, direitos humanos, justiça, comunicação, tecnologia, meio ambiente, trabalho e produção. As temáticas trabalhadas foram diversas de acordo com a necessidade do município e os conhecimentos de diferentes áreas do conhecimento que os acadêmicos tinham a oferecer. O Rondon proporciona a aproximação da academia com a sociedade, uma vivência de extensão na qual deveria ser oportuno à todos os acadêmicos vivenciar, pois nos aproxima do real e nos (trans) forma. Conclusão: acrescento em minha bagagem de experiências e aprendizados como rondonista, que todos devemos ser "sujeito da sua própria (trans)formação", encontrar sentido para o que estamos fazendo e ser implicados com a realidade das comunidades, que não é estável que se movimenta e modifica.
\end{abstract}

Palavras chaves: 1. Extensão. 2. Ensino/aprendizagem. 3. Práticas interdisciplinares. 4. Paulo Freire.

\section{THE EXPERIENCE OF A RONDONIST IN LIGHT OF PAULO FREIRE'S KNOWLEDGE}

\begin{abstract}
Introduction: As one of the main Extension Actions of Santa Catarina State University (UDESC), the Rondon Extension Center - NER/UDESC enables the exchange of scholars in different branches of
\end{abstract}


knowledge and the university's involvement in different scenarios of the state of Santa Catarina and other states in Brazil. Objective: To provide a report on Rondon's contribution in the educational process, a subtle approach based on a dialogue of discoveries over Paulo Freire's theoretical framework. Results: Four Operations were experienced through the Rondon Extension Center - UDESC: three as an academic in the nursing program in the Midwest of Santa Catarina and one working alongside a colleague in the coordination of the Operation. Amid the diversity of the extension workers from the different centers of knowledge, we develop activities with different individuals, from children to teenagers to youth to adults to the elderly. Given the diversity of the community, it was necessary to adapt different approaches to schoolchildren, health professionals, education professionals, public servants, community leaders, people with special needs, people in institutionalized environments or hospitalized, people who live in hard-to-reach places, among others. It was necessary to integrate the different sectors of society, such as education, culture, health, human rights, justice, communication, technology, environment, labor, and production. Various issues were addressed based on the needs of the municipality and the knowledge offered by the academics in different disciplines. Rondon enables an approximation between the academy and society, an extension experience which all academics should have the opportunity to experience, as it brings us closer to what is real and (trans)forms us. Conclusion: I add to my baggage of learning experiences as a Rondonist the understanding that we must all be the "subjects of our own (trans)formation," find meaning in what we are doing, and be involved with the reality of our communities, which is not stable. It moves and modifies.

KEYWORDS: 1 . University extension. 2. Teaching/learning. 3. Interdisciplinary practices. 4. Paulo Freire.

\title{
LA EXPERIENCIA DE UM RONDONISTA A LA LUZ DEL CONOCIMIENTE DE PAULO FREIRE
}

\begin{abstract}
RESUMEN
Introducción: el Centro de Extensión de Rondon - NER / UDESC, como una de las principales Acciones de Extensión de la Universidad del Estado de Santa Catarina (UDESC), ha estado posibilitando el intercambio de académicos en diferentes áreas del conocimiento y la inserción de la universidad en diferentes escenarios del estado Santa Catarina y otros estados de la federación. Objetivo: relatar el aporte de Rondon en el proceso formativo, de manera liviana y a partir de un diálogo de descubrimientos de los referentes teóricos de Paulo Freire. Resultados: fueron cuatro operaciones vividas por el Núcleo Extensionista Rondon - UDESC, tres de ellas como académica en el curso de enfermería en el Medio Oeste de Santa Catarina y una de ellas componiendo junto a un colega en la coordinación de la Operación. En la diversidad de extensionistas de diferentes centros de conocimiento, hemos desarrollado numerosas actividades con diferentes individuos desde bebés, niños, adolescentes, jóvenes, adultos hasta ancianos. En la diversidad de la comunidad, fue necesario adecuar los diferentes enfoques, como escolares, profesionales de la salud, profesionales de la educación, servidores públicos, líderes comunitarios, personas con necesidades especiales, personas en ambientes institucionalizados, otros hospitalizados, personas que viven en lugares de difícil acceso, entre otros. Era necesario integrar los diferentes sectores de la sociedad como educación, cultura, salud, derechos humanos, justicia, comunicación, tecnología, medio ambiente, trabajo y producción. Los temas trabajados fueron diversos según las necesidades del municipio y el conocimiento de las distintas áreas de conocimiento que los académicos tenían para ofrecer. Rondon brinda la aproximación de la academia a la sociedad, una experiencia de extensión en la que debe ser oportuna para todos los académicos, ya que nos acerca a las formas reales y (trans). Conclusión: agrego en mi bagaje de experiencias y aprendizajes como
\end{abstract}


rondonista, que todos debemos estar "sujetos a nuestra propia (trans) formación", encontrar sentido a lo que estamos haciendo e involucrarnos con la realidad de las comunidades, que es no estable si se mueve y modifica.

Palabras clave: 1. Extensión. 2. Enseñanza / aprendizaje. 3. Prácticas interdisciplinarias. 4. Paulo Freire.

\section{INTRODUÇÃO}

A universidade é um espaço que possibilita a agregação de inúmeros saberes heterogêneos. É a base indissociável para ampliar os conhecimentos e saberes, entre a extensão, o ensino e a pesquisa, que possibilita uma interação dialógica transformadora da Universidade com a sociedade (FERNANDES et al., 2012; SILVA et al., 2020).

As Diretrizes e Bases da Educação Nacional (LDB), conceitua, no Artigo 52, as universidades como "instituições pluridisciplinares de formação dos quadros profissionais de nível superior, de pesquisa, de extensão e de domínio e cultivo do saber humano" (BRASIL, 1996, art. 52). No artigo 43, apresenta a educação superior como as seguintes finalidades:

\footnotetext{
"I-Estimular a criação cultural e o desenvolvimento do espírito científico e do pensamento reflexivo; [...] VIEstimular o conhecimento dos problemas do mundo presente, em particular os nacionais e regionais; prestar serviços especializados à comunidade e estabelecer com esta uma relação de reciprocidade; VII- promover a extensão, aberta à participação da população, visando à difusão das conquistas e benefícios resultantes da criação cultural e da pesquisa científica e tecnológica geradas na instituição." (BRASIL, 1996, art. 43).
}

Nesse sentindo, Silva et al., (2020) compreendem que o ensino superior deve estar próximo da sociedade. No Brasil, a Política Nacional de Extensão Universitária, aprovada no ano de 2012, definiu a extensão universitária, como “[...] processos interdisciplinar, educativo, cultural, científico e político que promove a interação transformadora entre universidade e outros setores da sociedade" (FORPROEX, 2012, p. 28).

Para Freire (2010) a extensão é um processo de formação universitária que ocorre através de uma pedagogia crítica que facilita a construção de novos conhecimentos, percebendo o contexto social ao qual se está inserido (MIGUENS JR, CELESTE, 2014). Corrobora com o conceito de extensão universitária proposto no Fórum de Pró-Reitores de Extensão das 
Universidades Públicas Brasileiras- FORPROEX em 2006, que descreve a extensão como relação indissociável entre a universidade e a sociedade:

\begin{abstract}
"A extensão universitária Processo educativo, cultural e científico que articula o Ensino e a Pesquisa de forma indissociável e viabiliza a relação transformadora entre Universidade e Sociedade. A extensão é uma via de mão-dupla, com trânsito assegurado à comunidade acadêmica, que encontrará, na sociedade, a oportunidade de elaboração da praxis de um conhecimento acadêmico. [...]" (FORPROEX, 2006, p. 21)
\end{abstract}

O papel da Universidade deve se constituir em espaço de reflexão acerca das diferentes realidades, e dentro desse processo, possibilitar o desenvolvimento sustentável, cultural e social, por meio de ações extensionistas realizar atividades que são conduzidas de forma multidisciplinar para as comunidades e suas especificidades (SANTOS, CALIARI, SANTOS, 2017)

Nesse sentido destaca-se o Núcleo Extensionista Rondon - NER/UDESC, criado através da Portaria n 1192/2010, como uma das principais ações de Extensão da Universidade do Estado de Santa Catarina (UDESC), que vem possibilitando o intercâmbio dos acadêmicos em diferentes áreas de conhecimento e o inserção da Universidade em diversos cenários do estado de Santa Catarina e de outros estados da federação. Busca a garantia da interdisciplinaridade entre docentes, discentes, técnicos da universidade na interação com a sociedade, reforçando a missão da Universidade na formação diante da realidade social (NÚCLEO EXTENSIONISTA RONDON, 2018; BERTELLI, SANTOS, DEGGERONI, 2017)

A atuação extensionista tem proporcionado aos acadêmicos a percepção que a instituição de ensino cumpre com o princípio de que "[...] para a formação do profissional cidadão, é imprescindível sua efetiva interação com a sociedade, seja para se situar historicamente, para se identificar culturalmente e/ou para referenciar sua formação técnica com os problemas que um dia terá que enfrentar" (NOGUEIRA, 2000. p.120).

A extensão universitária permite a inserção dos discentes em diferentes cenários, experiência que favorece o reconhecimento das necessidades locais e implementação de ações (SANTOS, CALIARI, SANTOS, 2017). Nesse contexto, este artigo tem como objetivo relatar a contribuição do Rondon no processo formativo, de forma leve e baseada em um diálogo de descobertas a luz do referencial teórico de Paulo Freire. 


\section{O DIÁlOGo DAS DESCOBERTAS: O SER EXTENSIONISTA E O SER RONDONISTA}

A extensão universitária, está alicerçada nos princípios da integração ensino-pesquisa, teoria e prática, com intervenção diretamente na realidade da comunidade. Com uma postura em que a comunidade/sociedade deixa de ser passiva no recebimento das informações transmitidas pela universidade e passa a ser, participativa, crítica e construtora dos possíveis modos de organização e cidadania (RODRIGUES et al., 2013; SERRANO, 2010; JENIZE, 2004). Para Jenize (2004, [n.p]) a interação ensino-pesquisa-extensão é:

\footnotetext{
“[...] a interação ensino-pesquisa-extensão é o pilar que alicerça a formação humana/profissional, bem como a interação universidade e sociedade, no cumprimento da função social da universidade." É de fundamental importância que a universidade estabeleça a interação ensino-pesquisa-extensão, pois é o grande objetivo, para a formação de profissionais competentes.
}

A extensão universitária tem influência sobre a construção de uma sociedade livre, justa e solidária, assim como pode auxiliar no desenvolvimento nacional sustentável e reduzir desigualdades sociais (SANTOS, CALIARI, SANTOS, 2017). A boa prática extensionista pode, inclusive, aliando teoria e prática, contribuir para promover uma práxis auxiliadora de mudanças na sociedade (TENÓRIO, 2019). Enfim, a extensão é o que nos move a ação, executar aquilo que vimos na teoria, mas que só vem a enriquecer quando se é colocada em prática.

Conhecer a extensão através das vivências como rondonista é uma tarefa transformadora no qual todos acadêmicos deveriam vivenciar durante seu processo formativo. É preciso desprender-se das suas próprias concepções para acolher a realidade, estar aberto para vivenciar cada momento e para compreender o que cada encontro expressou, revelou e nos possibilitou conhecer. Em meio as recordações, cheias de sentimentos, cabe a difícil missão de traduzi-las em palavras, pois é nas experiências que nos constituímos "ninguém nasce feito, é experimentando-nos no mundo que nós nos fazemos" (FREIRE, 1993, p. 40).

Como graduanda do curso de enfermagem, no meu primeiro ano já realizava algumas ações de extensão por ser bolsista de um projeto de extensão denominado "Educação em Saúde" sob a coordenação da Professora Bernadette Kreutz Erdtmann, no qual articulávamos oficinas para comunidade sobre "Primeiros Socorros", "Cuidadores de idosos", "Parada 
Cardiorrespiratória" era nesse espaço "extracurricular" no qual reconhecia o sentido de "ser enfermeira", pois era o espaço naquele momento que possibilitava contato prévio com a comunidade. E foi por meio dele que tive o contato com a existência do NER-UDESC, quanto mais ouvia meus veteranos e as docentes compartilhar suas experiências mais interesse despertava em participar do concorrido e almejado processo seletivo da próxima operação.

Foram quatro Operações vivenciadas pelo Núcleo Extensionista Rondon - UDESC, três delas como acadêmica do curso de enfermagem do Centro Oeste Catarinense (CEO) e uma delas compondo junto com um colega na coordenação da Operação. Minha primeira operação foi a Operação Fronteira, realizada de 9 a 16 de julho de 2011, em 09 Municípios: Guarujá do Sul, Palma Sola, São José do Cedro, Anchieta, Dionísio Cerqueira e Princesa em Santa Catarina, Bom Jesus do Sul e Barracão no Paraná e Bernardo de Irigoyen-Argentina. Éramos 130 extensionistas, eu fiquei inserida no munícipio de Palma Sola com colegas da UDESC, Universidade de Brasília (UnB) e Instituto Federal de Santa Catarina (IFSC). Minha segunda Operação foi a Operação Caminho dos Tropeiros, realizada de 9 a 17 de dezembro de 2011, em 15 Municípios: Bom Retiro, Urubici, São Joaquim, Bom Jardim da Serra, Urupema, Rio Rufino, Bocaina do Sul, Palmeira, Otacílio Costa, Lages, Ponte Alta, Correa Pinto, São José do Cerrito, Anita Garibaldi e Capão Alto. Éramos 250 extensionista, eu fiquei inserida no município de Capão Alto, com colegas da UDESC, UnB, IFSC, Instituto Federal do Rio Grande do Sul (IFRS) Campus Sertão. Minha terceira Operação foi Operação Serra \& Mar, realizada no período de 25 de julho a 04 de agosto de 2012, em 07 municípios: Jacinto Machado, Praia Grande, Santa Rosa do Sul, Sangão, Morro da Fumaça, Urussanga e Lauro Müller. Éramos 175 extensionistas, eu fiquei inserida no município de Praia Grande, com colegas da UDESC, UnB, IFSC, Universidade Federal Fronteira Sul (UFFS) e Universidade Federal de Ciências da Saúde de Porto Alegre (UFCSPA).

Após um ano da conclusão da graduação, estava na residência multiprofissional da Atenção Básica da Escola de Saúde Pública do Rio Grande do Sul, participei de uma nova Operação Rio do Peixe, que ocorreu de 25 de fevereiro a 07 de março de 2015 em 15 municípios: Abdon Batista, Arroio Trinta, Curitibanos, Fraiburgo, Frei Rogério, Lebon Régis, Monte Carlo, Salto Veloso, Vargem, São Cristóvão do Sul, Zortéa, mas dessa vez com desafio maior de compor junto com um colega da UDESC na coordenação no município de Vargem com alunos da UDESC, UFFS e IFSC.

O Rondon tem sido um importante elo entre a universidade e a comunidade. Como extensionistas devemos nos comprometer em consolidar sempre mais ações voltadas a 
população de forma especial atividades segundo as necessidades do público foco, Freire (1985) afirma que o processo produtivo, antes de ser ato de produção, deve ser ato de descoberta das necessidades do povo para que possa responder a essas necessidades. Nesse sentido, como rondonista em um primeiro momento buscamos identificar as necessidades da população para propor ações que correspondam a realidade local. Por isso, cada operação do Rondon as necessidades se apresentam de formas diferentes, sendo necessárias adaptações aos diferentes públicos e contexto local.

Seria incapaz de descrever todas as oficinas, encontros, reuniões, ações que vivenciei nas operações do NER/UDESC. Diante dos diferentes núcleos de saber dos rondonistas desenvolvemos inúmeras atividades com indivíduos diversos, desde bebês, crianças, adolescentes, jovens, adultos até idosos. Na diversidade da comunidade, foi necessário adaptar as diferentes abordagens como para escolares, profissionais de saúde, profissionais da educação, servidores públicos, lideranças comunitárias, pessoas com necessidades especiais, pessoas em ambientes institucionalizados outras hospitalizadas, pessoas vivendo em locais de difícil acesso, entre outras. Por vezes, tivemos que dialogar e integrar ações com os diferentes setores da sociedade como a educação, cultura, saúde, direitos humanos, justiça, comunicação, tecnologia, meio ambiente, trabalho e produção.

As temáticas trabalhadas foram diversas de acordo com a necessidade do município e os conhecimentos de diferentes áreas do conhecimento que os acadêmicos tinham a oferecer. Exemplifico alguns dos temas abordados: coleta de lixo e meio ambiente, associativismo e cooperativismo, artesanatos com materiais descartáveis, capacitação para lideranças comunitários, atividades lúdicas para crianças, atividades físicas para idosos, inclusão digital, culinária, produção orgânica, artes cênicas para crianças, oratória, atendimento ao público, primeiros socorros, ética e profissionalismo para profissionais da saúde, oficina de reciclagem, horta comunitária, empoderamento dos Agentes Comunitários de Saúde (ACS), educação sexual e tinha também o Cine Rondon. A não poderia deixar de descrever as atividades que ressignificaram o fazer junto para e com a comunidade como o plantio de árvores, restauração e pintura de um espaço comunitário, talvez a mais marcante das minhas experiências o levantar de uma estrutura feita de barro e materiais reutilizável que ficaria como ponto de geração de renda para venda de produtos da comunidade quilombola.

Essas atividades foram desenvolvidas nos períodos diurno e noturno, a partir de um cronograma construído junto com a comunidade local, cujas atividades foram dispersas conforme aptidão e o desafiar-se dos rondonistas em assumir a realização de atividades de 
cunho multidisciplinar, Dagnino (2015) descreve que por muitas vezes na universidade o que fizemos é orientado por disciplinas e cabe o desafio de situar as problemáticas diante de um contexto socioeconômico de um fazer multidisciplinar.

Para traduzir essa multidisciplinariedade que se faz no dia a dia de uma operação do Rondon, utilizo o conceito de Morin (1990) sobre a complexidade que significa o que é/foi tecido junto, quando elementos diferentes são inseparáveis e constitutivos do todo; constituintes heterogêneos inseparavelmente associados. Essa, por sua vez é entendida como conexão interdependente ente as partes e o todo, o todo e as partes e as partes entre si. Integram dessa forma, os acontecimentos, ações, interações, retroações, determinações e acasos que constituem o mundo fenomênico. (MORIN, 2006).

Cada Operação é como um tecido que foi constituído de partes formando o todo. São partes vindas de vários lugares, diferentes núcleos profissionais, bagagens de conhecimentos diversos, para se "juntar" a outras partes de uma comunidade que já está tecendo sua história, seus costumes, seus valores e com seus saberes. No primeiro dia somos "uma parte" que dia a dia vamos tecendo com outras partes, entrelaçando conhecimentos, experiências, vivências, histórias de vida e tudo aquilo que no início era uma parte logo está junto, formando um todo, que embora formando uma unidade não se destrói a riqueza da diversidade e variedade das partes que foram tecendo para formar o todo.

Durante os dias de inserção na comunidade, o conhecimento vai se tecendo, encontro a encontro, valorizando o conhecimento prévio pessoal dos colegas, mas acima de tudo da comunidade, reconhecendo as necessidades de buscar novos recursos para aperfeiçoar a troca de aprendizagem. Nesse movimento, é possível identificar que exige do aluno uma postura ativa, ética, proativa, criativa de responsabilidade consigo e com o coletivo, em que o conhecimento explora e desenvolve habilidades críticas-reflexivas, para a construção de uma nova síntese do saber, é quando percebemos que constantemente estamos nos (re) (des) construindo enquanto sujeitos que se constroem nas relações humanas com o mundo. Para Freire (2006 p. 36) "o conhecimento não se estende do que se julga sabedor até aqueles que se julga não saberem; o conhecimento se constitui nas relações homem-mundo, relações de transformação, e se aperfeiçoa na problematização crítica destas relações."

Nesse sentindo em cada Operação do Rondon se constrói muito conhecimento, na relação que ocorre na micro dimensão (indivíduo) até macro dimensão (coletivo/comunidade) e assim na multidimensionalidade das realidades, que abarcam os aspectos culturais, sociais, históricos, ecológicos assim que vamos transformando e sendo transformados, segundo Freire 
"se, na experiência de minha formação, que deve ser permanente, começo por aceitar que o formador é o sujeito em relação a quem me considero o objeto, que ele é o sujeito que me forma e eu, o objeto por ele formado. (FREIRE, 1996. p. 13). Hoje faço a leitura de como o Rondon foi um "sujeito" que me formou, e eu fui um objeto por ele (trans)formada.

\section{DIALOGOS DAS EXPERIÊNCIAS: O RONDON QUE (TRANS) FORMA}

O projeto Rondon é indescritível, só quem vive consegue sentir a intensidade de dez dias que traduzem os momentos mais simples nas lembranças mais profundas. Já discutia Freire (1969) a importância do ato do diálogo entre a sociedade e toda a comunidade acadêmica. O Rondon proporciona essa aproximação da academia com a sociedade, uma vivência de extensão na qual deveria ser oportuno a todos os acadêmicos vivenciar, pois nos aproxima do real e nos (trans) forma.

No Rondon, nos reconhecemos como seres que estão em constante (re) (des) construção de saberes "O homem, como um ser histórico, inserido num permanente movimento de procura, faz e refaz constantemente o seu saber". (FREIRE, 1981, p. 47). Nesse movimento de procura, fui em busca de novas descobertas, nos campos desconhecidos do saber, busquei reconhecer que estamos em permanente construção, e a produção do conhecimento se dá das nossas relações com os outros e com o mundo a partir das experiências.

Durante esse caminhar de rondonista, me foi oferecido condições para que pudesse assumir-se como ser histórico, como ser pensante, comunicante, transformadora, criadora pois para Freire a "autonomia vai se constituindo na experiência de várias, inúmeras decisões que vão sendo tomadas" (FREIRE, 2002. p. 67). O Rondon foi um dos grandes disparadores de muitas discussões, emoções, embates, crescimento, escuta, abertura, consenso e pactuação. Conviver e pensar de forma coletiva exige reflexão que quando realizada no individual a vemos sob a percepção do "eu", considerando a bagagem pessoal, quando levada a um grupo o olhar se amplia, e as possibilidades de outras reflexões surgem. Não visando o "certo" ou "errado", mas sim a possibilidade da discussão, e isso é muito enriquecedor, pois favorece a identificação de obstáculos e oportunidades para uma potente articulação de trabalho em equipe. Ainda, possibilita o acompanhamento e avaliação do desenvolvimento das ações, promove uma construção de um cuidado uns com os outros e também apoia a produção de novos conhecimentos. 
No Rondon aprendi que não existe o "eu" existe "nós", existe um coletivo que se faz na diversidade de gêneros, idades, etnias, culturas e valores, somos pessoas diferentes, vindas de locais diferentes, de núcleo de formação diferentes, com bagagens diferentes, e são nessas diferenças que se colocamos próximos, juntos a uma comunidade para uma intensa experiência de extensão que segundo Paulo Freire (1983.p.69) "não é a transferência de saber, mas um encontro de sujeitos interlocutores que buscam a significação dos significados". Ainda, para Freire (1992) a compreensão da extensão, trabalha com o conhecimento que exige uma presença curiosa do sujeito em face do mundo, demanda uma busca contínua de ação transformadora sobre a realidade, assim implica na invenção e reinvenção constante. Desta forma, o Rondon contribuiu no desenvolvimento de habilidades como a comunicação, a relação inter-pessoais, o compromisso, a organização, a pró atividade, curiosidade, a criatividade e necessidade de se desafiar diante do "imprevisto" enfrentando medos de inseguranças e incapacidades, se (re) inventando constantemente.

No Rondon aprendemos o que os livros não são capazes de traduzir. Na interação para e com o outro que sentimos as mais diversas emoções, os olhos transbordam nos pequenos encontros, as histórias que marcam as vidas, os sorrisos que se revelam em vários momentos, os abraços que traduzem os agradecimentos e a aprendizagem que se (re) (des) constrói continuamente. São tantas descobertas, talvez a maior delas é que podemos ser rondonista todos os dias com consciência crítica e reflexiva sobre a sociedade, sobre nossa responsabilidade cidadã, e hoje trago a extensão na minha vida pessoal e na prática profissional.

Como enfermeira entendi que se produz saúde com a comunidade, aprendi a importância de uma escuta ativa e mais sensível com um olhar ampliado e humanizado, ancorado nas Políticas de Saúde. Aprendi a contextualizar a necessidade de saúde de determinada comunidade, a re (conhecer) os contextos em que as pessoas estão inseridas que este usuário/família/comunidade constituem vínculos territoriais, e que os determinantes sociais de saúde precisam ser considerados. Aprendi a potência do trabalho em equipe, que precisamos ter um olhar ampliado para as ações em saúde de forma multiprofissional e intersetorial, visando um cuidado integral. Aprendi que como profissional tenho um compromisso social com o fortalecimento do Sistema Único de Saúde (SUS), que posso buscar por melhoria das práticas em saúde seja como trabalhadora do SUS e como docente formadora de profissionais de saúde.

Nessas concepções, entendi a importância do acolhimento diante das necessidades das pessoas e populações, considerando suas singularidades/particularidades, o perfil 
epidemiológico e o modo como se constitui o viver do indivíduo/família/comunidade e com o fazer junto podemos ser (trans) formadores.

\section{DIALOGOS DAS TRANSFORMAÇÕES: CONCLUINDO O PERCURSO}

Das partes constituiu-se o todo, inacabável, inseparável, uno e múltiplo, formou-se uma colcha de retalhos, em que tecendo as partes (acontecimentos, ações, reflexões, sentimentos, avaliações), se constitui o Todo (operação).

As operações do NER/UDESC mobilizam e desacomodam, como sujeita cidadã, possibilita ao rondonista vivenciar realidades diferentes, numa perspectiva de integração social, desenvolvimento local e criação e fortalecimento do vínculo entre academia e comunidade.

A diversidade de ações realizadas junto com a comunidade oferece e proporciona ao aluno diferentes oportunidade de aprendizagem significativa, contribuindo no desenvolvimento de competências pessoais e profissionais. Assim, entendo o NER como ferramentas potente de formação, por favorecer a (trans)formação de profissionais em sujeitos ativos, críticos e reflexivos sobre seu processo de trabalho e sobre seu próprio papel como cidadão.

No percurso de rondonista, fui acrescentando em minha bagagem de experiências que a aprendizagem é construtiva, participativa e afetiva, no predomínio do discurso dialógico, em que o saber crítico-reflexivo é proporcionado pela construção do conhecer coletivo, que parte das experiências prévias se confrontando com novos conhecimentos. Ainda, inserida em realidades que me tornaram mais consciente de meu papel social, minha maior bagagem, durante meu processo formativo, foi fazer parte do NER/UDESC, e muito mais o NER ser parte de mim. Quem vive e assume o ser rondonista, carrega o compromisso de ser "sujeita da (trans)formação".

\section{REFERÊNCIAS}

BRASIL. Lei n. 9.394, de 20 de dezembro de 1996. Estabelece as diretrizes e bases da educação nacional. Brasília: Presidência da República; Casa Civil, 1996. Disponível em: http://www.planalto.gov.br/ccivil_03/leis/19394.htm. Acesso em: 21 abr. 2020.

Silva et al., (2020).

BERTELLI, V; SANTOS, A.B; DEGGERONI, M.V.R. Núcleo extensionista rondon NER/UDESC e a concepção da extensão universitária como fomento acadêmico. 2017. Disponível em: 
https://www.researchgate.net/publication/335378033_Nucleo_extensionista_rondon_NERUDESC_e_a_concepcao_da_extensao_universitaria_como_fomento_academico Acesso em: 02.fev. 2021

DAGNINO, Renato. Como É a Universidade de que o Brasil Precisa? Avaliação, Campinas, Unicamp, v. 20, n. 2, p. 293-333, 2015.

FERNANDES, Marcelo Costa et al . Universidade e a extensão universitária: a visão dos moradores das comunidades circunvizinhas. Educ. rev., Belo Horizonte, v. 28, n. 4, p. 169194, Dec. 2012. Available from http://www.scielo.br/scielo.php?script=sci_arttext\&pid=S0102$46982012000400007 \& \operatorname{lng}=$ en $\&$ nrm $=$ iso. access on 20 Mar. 2021. https://doi.org/10.1590/S0102-46982012000400007.

FORPROEX. Fórum dos Pró-Reitores de Extensão das Universidades Públicas Brasileiras. Indissociabilidade Ensino Pesquisa. Extensão e a Flexibilização Curricular: uma visão da Extensão. Porto Alegre: UFRGS ; Brasília: MEC/SESu, 2006.

FORPROEX. Fórum dos Pró-Reitores de Extensão das Universidades Públicas Brasileiras. Política Nacional de Extensão Universitária. Manaus: FORPROEX, 2012. Disponível em: http://proex.ufsc.br/files/2016/04/Pol\%C3\%ADtica-Nacional-de-Extens\%C3\%A3oUniversit\%C3\%A1ria-e-book.pdf. Acesso em: 4 jan. 2021.

FREIRE, P. Educação como prática da liberdade. 2. ed. Rio de Janeiro: Paz e Terra, 1969. p. 150.

FREIRE, Paulo. Educação como prática da liberdade. Rio de Janeiro: Paz e Terra, 1981, p.47.

FREIRE, Paulo. Por uma Pedagogia da Pergunta. Coleção educação e comunicação. Rio e Janeiro: Paz e Terra, 1985. v.15

FREIRE, P. Extensão ou comunicação? 10. ed. Rio de Janeiro: Paz e Terra, 1992

FREIRE, Paulo. Política e educação. São Paulo: Cortez Ed., 1993.

FREIRE, Paulo. Pedagogia da autonomia: saberes necessários à prática educativa. $22^{\mathrm{a}}$ edição. São Paulo: Paz e Terra, 2002.

FREIRE, Paulo. Extensão ou Comunicação. 13a Edição. São Paulo: Paz e Terra. 2006

FREIRE, Paulo. Extensão ou Comunicação? 14 ed. Rio de Janeiro: Paz e Terra; 2010

JENIZE, Edineide. As Práticas Curriculares e a Extensão Universitária. 2004.

MIGUENS JR. Sérgio Augusto Quevedo e CELESTE, Roger Keller. A extensão universitária. 2014. Disponível

em: https://www.researchgate.net/publication/253645827_A_EXTENSAO_UNIVERSITARI A__Capitulo_de_Livro. Acesso em: 10. mar.2021 
MORIN, Edgar. Introdução ao pensamento complexo.3.ed. Lisboa: Instituo Piaget, 1990

MORIN, Edgar. Introdução ao pensamento complexo. Porto Alegre (RS): Sulina, 2006.

NOGUEIRA, Maria das Dores Pimentel (org.). Extensão universitária: diretrizes

conceituais e políticas. Belo Horizonte: Fórum Nacional de Pró-Reitores de Extensão das Universidades Públicas- UFMG, 2000. 193 p.

NÚCLEO EXTENSIONISTA RONDON (NER), 2018. Disponível em: https://www.udesc.br/nucleorondon. Acesso em: 24 jul. 2018.

RODRIGUES, A. L. L; PRATA, M.S; BATALHA, T.B.S et al,. Contribuições da extensão universitária na sociedade. Cadernos de Graduação - Ciências Humanas e Sociais. Aracaju: 2013. v. 1, n.16, p. 141-148. 2013

SANTOS, V.M. M; CALIARI, F. M; SANTOS, A.B. Anais $7^{\circ}$ Congresso Brasileiro de Extensão Universitária. Extensão Universitária e responsábilidade social: resultados do núcleo extensionista Rondon da Universidade do Estado de Santa Catarina- NER/UDESC. 2016. Disponível em: https://cbeu.ufop.br/anais_files/568f8b87391ffb725ffbbbb533c32819.pdf Acesso em: 22.fev. 2021

SERRANO, Rossana Maria Souto Maior. Conceitos de extensão universitária: um diálogo com Paulo Freire. 2010. Disponível em:

https://www.ets.ufpb.br/pdf/2013/1\%20Universidade\%20e\%20Sociedade/US\%2013_Texto\% 201\%20Serrano_Conceitos\%20de\%20extensao\%20universitaria.pdf

SILVA, Márcia Regina Farias; MASCARENHAS, Anne Lizabelle Leite Duarte; DUTRA, Maria da Conceição Farias da Silva Gurgel; SILVA, Carlos Aldemir Farias; DIAS, Nildo da Silva. Reflexões sobre as ações extensionistas e de pesquisa no combate à COVID-19 na universidade do estado do Rio Grande do Norte. Brazilian Journal Of Health Review, [S.L.], v. 3, n. 2, p. 3622-3646, 2020. Brazilian Journal of Health Review. Disponível em: http://dx.doi.org/10.34119/bjhrv3n2-191. Acesso em: 29 out. 2020.

TENÓRIO, Fernando Guilherme. Apresentação do dossiê. Revista Debates Insubmissos. Caruaru: 2019, v.2, n. 6, p. 2595-2803. Disponível em:

https://periodicos.ufpe.br/revistas/debatesinsubmissos/ Acesso em: 29 out. 2020.

UNIVERSIDADE DO ESTADO DE SANTA CATARINA (UDESC). Portaria $\mathrm{n}^{\circ} 1192$, de 18/08/2010. Designa Núcleo Projeto Rondon. Diário Oficial da Universidade do Estado de Santa Catarina, Florianópolis, SC, 23 de ago. 2010. 